«Системні технології» 3 (128) 2020 «System technologies»

DOI 10.34185/1562-9945-3-128-2020-06

УДК 004.932.72'1

Н.О. Соколова

\title{
ІНФОРМАЦІЙНА ТЕХНОЛОГІЯ АВТОМАТИЗОВАНОГО РОЗПІЗНАВАННЯ БУДІВЕЛЬ
}

Анотація. Дана робота присвячена опису розробленої інформаційної технології для задач розпізнавання будівель на знімках дистанційного зондування Землі високої роздільної здатності та верифікації результатів розпізнавання. Проаналізовані сучасні підходи до розпізнавання будівель. Запропонована технологія заснована на аналізі гістограм та сегментації в просторі ознак. Для верифікації результатів розпізнавання розроблені методики на основі геометричного аналізу, тіньового аналізу та використання метаданих. Результатом роботи є векторний файл, який містить розпізнані багатокутні об'єкти. Ключові слова: сегментація, тіньовий аналіз, геометричний аналіз, розпізнавання будівель, дистанційне зондування, гістограма, сцена, фотограмметричні зображення.

Вступ та постановка проблеми. Щорічно зростає частка космічних знімків в загальній масі даних дистанційного зондування Землі. Підвищується якість даних одержуваних із супутників, збільшується точність, знижується ціна, значно підвищується продуктивність нових супутників. Аналіз сучасних методів розпізнавання будівель показав недосконалість використання окремих методик та алгоритмів, малу кількість інформаційних технологій автоматичного розпізнавання будівель та необхідність розробки комплексного підходу для вирішення цього питання. Автоматичне розпізнавання будівель допомагає заощадити час та системні ресурси на оновлення баз даних геоінформаційної системи та підтримання сучасних муніципальних геодезичних даних. У той же час автоматичне розпізнавання супутникових знімків високої роздільної здатності не є ефективним через високу неоднорідність спектральних, текстурних та просторових характеристик. Окрім «бажаних» об’єктів (будинки та дороги), зображення високої роздільної здатності включають

(C) Соколова Н.О., 2020 
«Системні технології» 3 (128) 2020 «System technologies»

об’єкти, які заважають просторовому розпізнаванню (наприклад, дерева, машини та найголовніше тіні).

Виявлення змін штучних об’єктів земної поверхні тісно пов’язане з багатьма прикладними задачами охорони навколишнього середовища, екологічної безпеки, оперативного моніторингу міських забудов, оцінки збитків і наслідків, спричинених стихійними лихами чи діяльністю людства.

Аналіз останніх досліджень. Останні публікації пропонують розпізнавання будівель на фотограмметричних зображеннях високої роздільної здатності на основі багатоетапних методик або об'єктноорієнтованого підходу [1,2]. У процесі аналізу отриманих при сегментації об'єктів вилучається рослинний покрив за допомогою нормалізованого диференційного вегетаційного індексу (NDVI), знаходження тіней об'єктів за допомогою яскравості і спектральних характеристик і їх фільтрація, а також використовується інформація про взаємне розташування сегментів зображення і кутові характеристики. В якості дешифрувальної ознаки використовують тон пікселів. В [3] запропоновано інформаційну технологію розпізнавання будівель у багатоканальних фотограмметричних зображеннях високого просторового розрізнення на основі морфологічних індексів. Останнім часом збільшилася кількість публікацій, в яких пропонують використовувати різноманітні нейромережеві підходи для розпізнавання будівель на зображеннях дистанційного зондування високої роздільної здатності [4-6].

Формулювання цілей статті. Метою дослідження $є$ розробка інформаційної технології автоматизованого розпізнавання будівель на фотограмметричних зображеннях високого просторового розрізнення. Необхідно розробити алгоритм розпізнавання будівель; провести оцінку якості та інтерпретації отриманих результатів розпізнавання; розробити методику верифікації результатів розпізнавання; на базі запропонованих алгоритмів та методик розробити автоматизовану інформаційну технологію розпізнавання будівель на фотограмметричних зображеннях.

Основна частина. При розпізнаванні будівель необхідно враховувати комплексні характеристики, які неможливо описати простою 58 
«Системні технології» 3 (128) 2020 «System technologies»

геометрією; виявлення краю і лінії сегментації не може бути єдиним рішенням в процесі розпізнавання; необхідно враховувати сигнали глибини (наприклад тіні); треба прагнути спрощення процедури розпізнавання; для доповнення рішення можна використовувати метадані ГІС. Розроблена технологія заснована на інтеграції джерел дистанційного зондування і наявних даних ГІС на етапах початкового спрощення та подальших етапах валідації. Технологія складається з наступних етапів (Рис.1):

1. Розбиття зображення на ділянки з елімінацією вільних ділянок і визначення типу ділянки.

2. Аналіз гістограми.

3. Сегментація ознак в просторі зображення.

4. Валідація на основі аналізу розмірів, геометричного та тіньового аналізу.

5. Знаходження і узагальнення контуру будівлі.

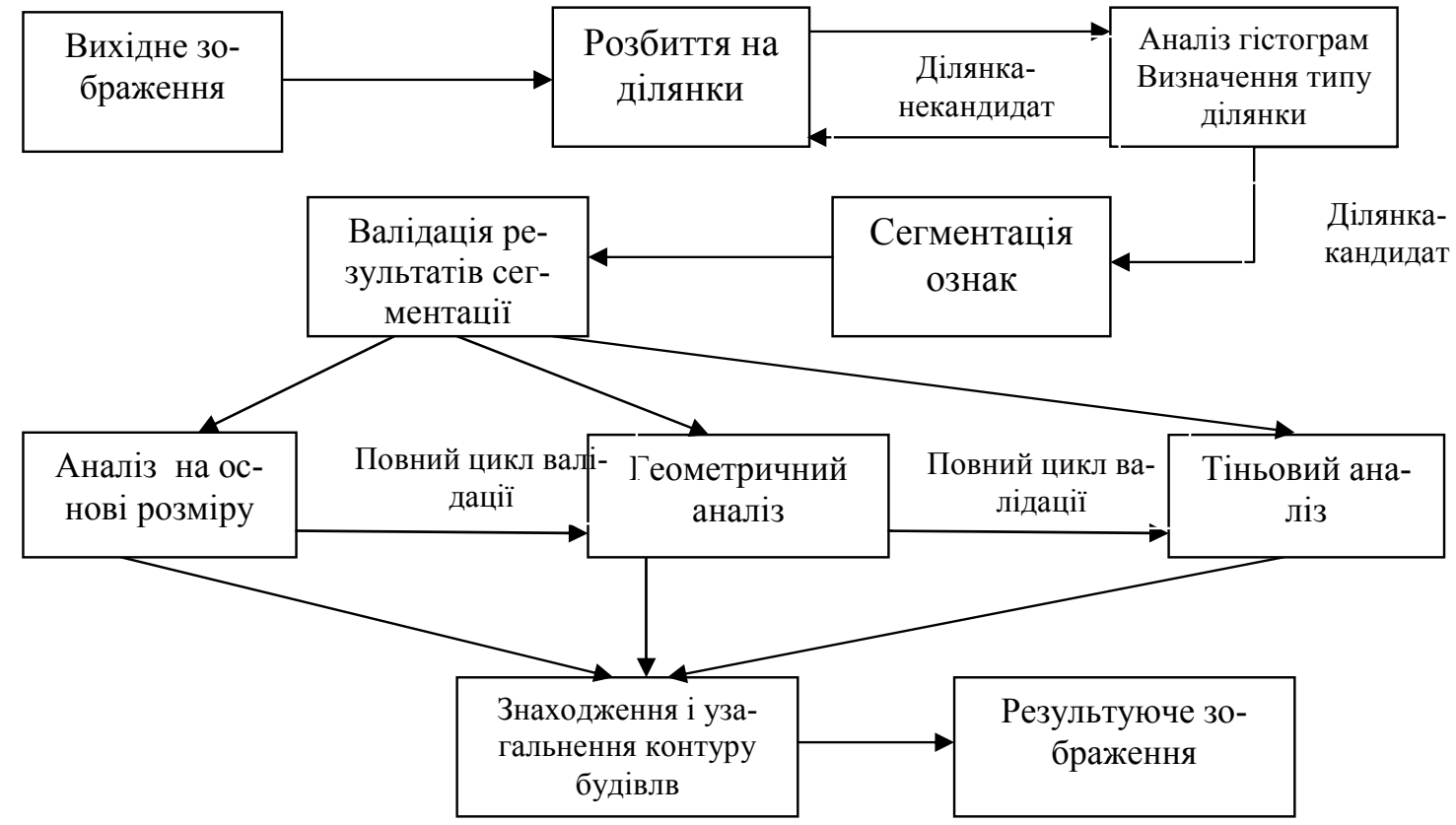

Рисунок 1 - Інформаційна технологія автоматизованого розпізнавання будівель

На першому етапі зображення розбивається на сегменти для локалізації пошуку та первинного спрощення сцени розпізнавання. Експертні атрибути ділянки використовуються для вилучення порожніх ділянок та визначення типів ділянок (житлова забудова, багатоповерхова або коме- 


\section{«Системні технології» 3 (128) 2020 «System technologies»}

рційна), що полегшує процес розпізнавання. Інформація про територіальне зонування кожної ділянки може бути використана для виділення області ділянки, яка найімовірніше, містить будівлю. Для кожної сцени в межах зображення створюється нове, менше, зображення розміром 3 ділянку, яка $є$ потенційною ділянкою, що містить будівлю. Область поза потенційною ділянкою приймає значення 0 (чорний фон).

Попередні дослідження деяких зображень показали стабільну генерацію піків гістограми для даху будівлі, тобто будівлі є домінантними особливостями в межах ділянки [7]. Оскільки ділянка - кінцевий двовимірний простір з обмеженим числом особливостей, будівля охоплює значну кількість пікселів - по суті пік у всіх 3 смугах. У великій вибірці будівель в тестових зображеннях, було помічено, що близько 50\% ділянок містять будівлі, які створюють мажоритарний пік. В інших випадках, будівля генерує пік, але не мажоритарний, а в деяких випадках існує більш ніж один будинок або комплекс будівель на ділянці. У деяких випадках тінь, яка $є$ невід'ємною частиною будь-якого висотного об'єкту, дає на гістограмі піки, що конкурують з мажоритарним піком, також бувають випадки, коли на гістограмі немає єдиного мажоритарного піку. Для визначення порогу кожного піку, технологія знаходить високу точку-пік, а потім шукає низьку "сідлову" точку, де схил стає більш помірним або повністю змінується напрям. Грунтуючись на "сідлових" точках, визначається граничне значення для кожного піку в кожному діапазоні. Потім всі три смуги корелюються для ідентифікації об'єкта у всіх трьох діапазонах. Через локальності пошуку для забудови в межах ділянки аналіз гістограми дає легку кореляцію між об'єктами і піками гістограми. На основі аналізу гістограми, відповідні особливості сегментуються в просторі зображення. Далі пікселі згруповуються в чіткі об'єкти. Кожен піксель перевіряється на відповідність інформації піків. Якщо виявлено, що значення пікселя знаходиться в межах інтервалу певного піку (у всіх трьох смугах), нове значення пікселя - це пікове значення. Пік може представляти повну особливість (потенційну будівлю), її частину або кілька об'єктів з подібними спектральними характеристиками. 3 метою згладжування та усунення порожнин сегменти піддаються подальшій обробці. 
«Системні технології» 3 (128) 2020 «System technologies»

Наступні етапи є механізмом оцінки ймовірності сегмента бути частиною будівлі, а саме аналізи розміру, тіні і геометрії сегментів. Аналіз розмірів грунтується на експертних атрибутивних даних. Обмеження за розміром може використовуватися, щоб усунути сегменти, отримані особливості яких не відповідають експертним даним ділянки. Обмеження розміру оцінюється або за допомогою площі, взятої з таблиці атрибутів, або обчислюється як мінімальний відсоток розміру ділянки. Експертні дані використовувалися для навчання нейромережі, яка далі оцінює можливість сегмента бути будівлею.

Відсів сегментів із низькою ймовірністю бути будівлею базується також і на геометрії $[8,9]$. Геометричний аналіз заснований на загальних мірах для подання геометричних характеристик сегмента. Значення мір, що відносяться до сегментів з будівлями і без, використовуються для елімінування сегментів на основі показника ймовірності. Для оцінки геометричної ймовірності, що це будівля, обчислюються наступні параметри: прямокутність і еліптичність сегмента, масивність, опуклість і компактність. Дані характеристики перевіряються індивідуально шляхом порівняння поведінки параметра для об'єктів «будівля» і «не будівля». Для того, щоб використовувати ці міри для розрахунку ймовірності для сегмента бути сегментом з будівлею, вони повинні бути різними для класів з будівлями і без будівель відповідно. Значення кожного параметра потім використовується для обчислення ймовірності сегмента «бути будівлею». Використовуються прості обмеження, такі як мінімальна ширина будівлі (для простору, придатного для житла або використання в якості робочої зони). Можливість наявності порожнин в межах сегмента оцінюється як показання для виключення сегмента (порожнини, більші ніж очікується, будуть індикатором відсутності будівлі). На цьому кроці для виключення контурів "не-будівель» використовуються інваріантні моменти Ху. Розроблений метод на даному етапі дозволяє пом'якшити вплив етапу сегментації, визначивши граничне значення для порівняння розмірів і кілька геометричних мір (округлість, монолітність, опуклість, компактність), що визначають відповідну ймовірність сегмента. 
«Системні технології» 3 (128) 2020 «System technologies»

На етапі тіньового аналізу користувач забезпечує просту індикацію напрямку освітлення сонцем. Знання загального напрямку сонячного освітлення може допомогти розрізняти сегменти, які мають тінь на коректній позиції і відносяться до сегментів з будівлями, і сегменти 3 «некоректною» тінню, і відповідно, не є будівлями [10]. Наявність метаданих в складі даних ДЗ3, а також просторових даних у вигляді векторних карт території зйомки дозволяє проводити аналіз узгодженості об'єктів і тіней на зображенні. Тінь повинна знаходитися в певному положенні щодо об'єкта, в нашому випадку - будівлі. Знання напрямку сонячного освітлення може допомогти розрізняти сегменти, які мають тінь на коректній позиції, як сегменти з будівлею від сегментів, які не є будівлею. Рішення задачі грунтується на аналізі значень числових характеристик зображення, що прямо залежать від параметрів зйомки: положення Сонця, положення космічного апарату і орієнтації пристрою реєстрації. у більшості випадків у будівель на зображеннях високої роздільної здатності присутні дві тіньові області: тінь будівлі на землі (падаюча тінь), яка обумовлена сонячним освітленням, і самостійна тінь (затінена частина об'єкта). Положення падаючої тіні можна визначити, знаючи час і напрямок зйомки. Зазначені параметри зйомки, як правило, супроводжують в якості метаданих геопросторові зображення, отримані з аерокосмічних носіїв.

Після сегментації, яка заснована на аналізі гістограм і проводиться у всіх трьох RGB-каналах, пікселі з певними значеннями групуються в сегменти (сегменти «особливостей» і сегменти тіні). Аналіз тіні заснований на вихідному "тіньовому образі", створеному в результаті тіньової сегментації. Результатом тіньового аналізу є зображення з одним або декількома сегментами, які залишаються в якості можливих кандидатів бути будівлями. Через складність тіньового аналізу в міських умовах, не виключаються сегменти, для яких є невизначеність, щодо достовірності сегмента бути будівлею, і вони можуть бути додатково досліджені.

Етапи геометричного, тіньового аналізу і аналізу розміру використовуються як механізм для оцінки чи є сегмент частиною будівлі. Сегменти, які визначені як не-будівлі, на основі різних мір, будуть вилучені. 62 
«Системні технології» 3 (128) 2020 «System technologies»

Для інших, до кожного сегмента додається оцінка ймовірності як оцінка міри для користувача в кінцевому підсумку.

Результат сегментації зображення - растрове зображення розпізнаних сегментів, які повинні бути геометрично проаналізовані і конвертуються у векторний полігональний шар в якості кінцевого результату і можуть використовуватися для можливої ручної постобробки. На цьому ж етапі проводиться узагальнення з метою усунення невеликих западин або виступів. Результатом всього процесу є векторний файл, який містить багатокутні об'єкти, а також ймовірні багатокутники, які можуть бути будівлею (Рис.2).

Гістограми всіх ділянок визначають їх як ділянки - потенційні кандидати з будівлями. Етап тіньового аналізу відкидає третю ділянку як ділянку із будівлею (тінь знаходиться 3 «невірного» боку). Завдяки темному даху будівля на першій ділянці розпізнана частково, в цьому випадку необхідна ручна постобробка для коригування результатів розпізнавання.

Висновки. Технологія автоматичного розпізнавання була протестована для різних сценаріїв: повний прогін, включаючи всі три етапи аналізу; виключаючи аналіз розмірів; виключаючи аналіз тіней; виключаючи аналіз геометрії. Кожен запуск забезпечує можливість ізолювати вплив певного етапу на процес розпізнавання, отже, оцінити вигоду для всього процесу. Аналіз комерційних будівель виявив, що повний прогін, який включає в себе всі етапи, підвищує загальну точність розпізнавання і знижує обсяг ручної постобробки. Аналіз геометрії є вирішальним кроком в загальному процесі зі значними впливом на кінцевий результат. Аналіз розмірів і аналіз тіні також грають важливу роль і повинні бути інтегровані в процес, щоб зменшити зусилля постобробки. 
«Системні технології» 3 (128) 2020 «System technologies»
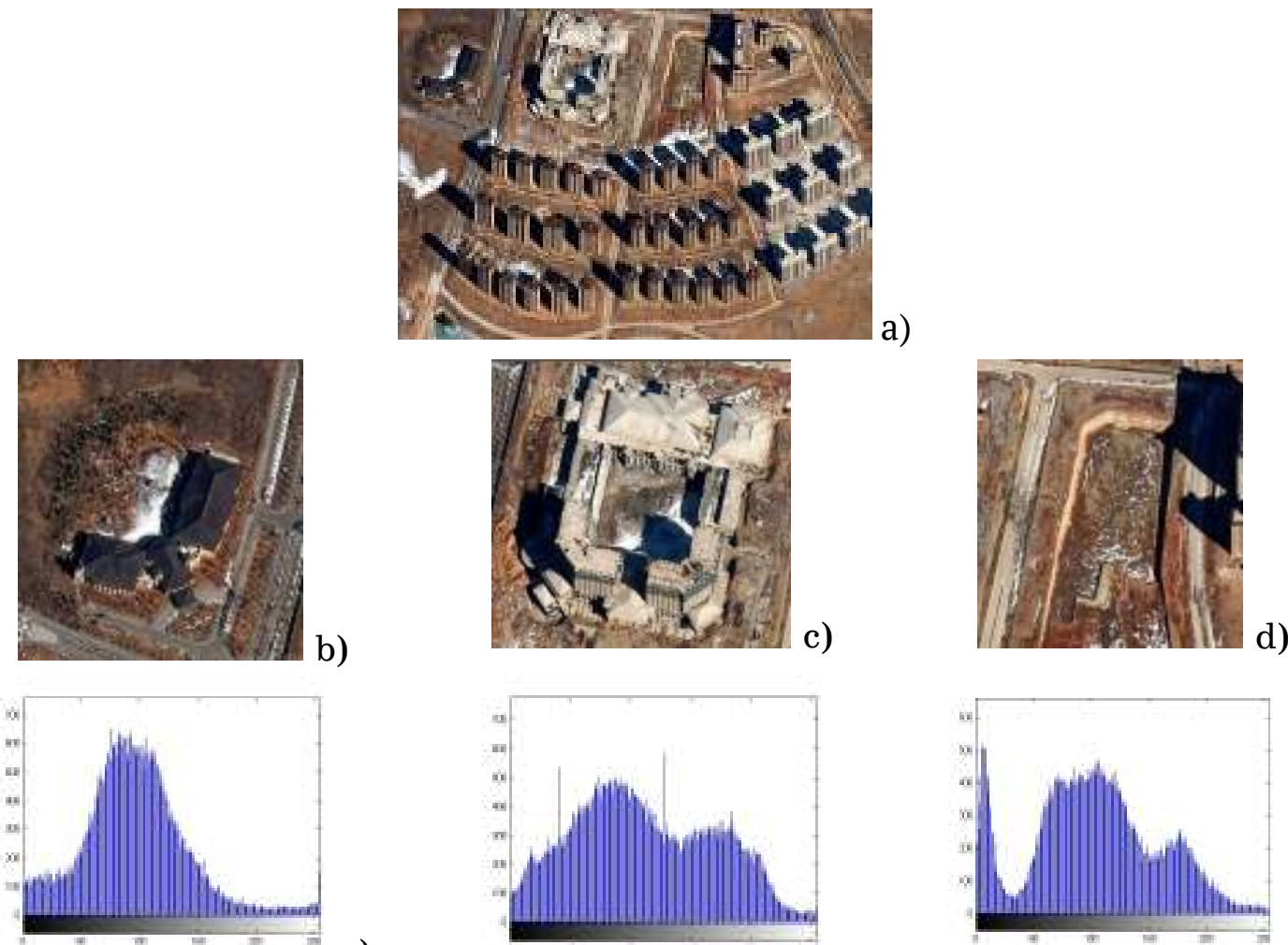

e)
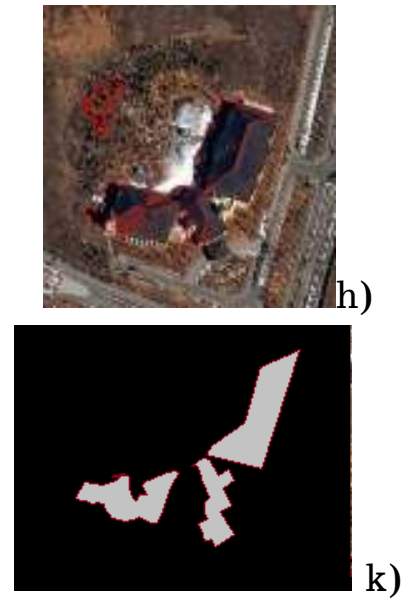

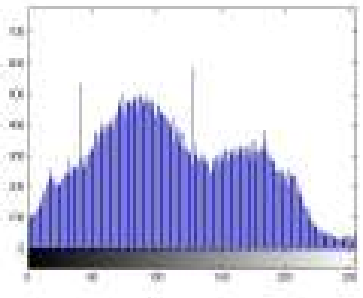

f)

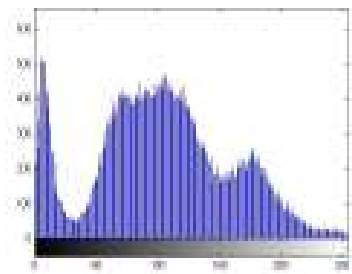

g)
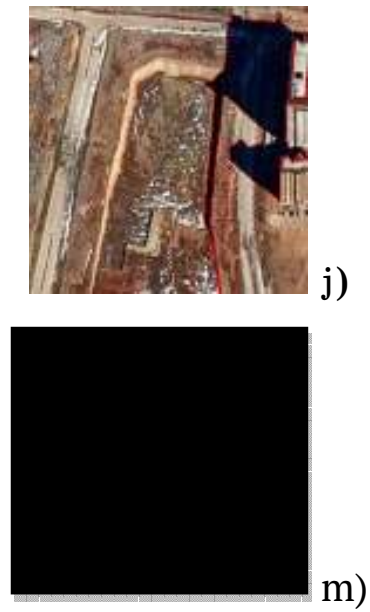

Рисунок 2 - Етапи розпізнавання: а- вихідне зображення; b, c, d розбиття ділянки; е, f, g аналіз гістограми ; h,i,j - тіньовий аналіз; k, l, m результуюче зображення

\section{ЛІТЕРАТУРА / ЛИТЕРАТУРА}

1. Shedlovska Y.I. Shadow detection and removal using a shadow formation model / Y.I. Shedlovska, V.V. Hnatushenko // Proceedings of the 2016 IEEE 1st International Conference on Data Stream Mining and Processing, 2016, August, 23 - 27, Lviv, Ukraine, pp.187-190. 
«Системні технології» 3 (128) 2020 «System technologies»

2. R.Ghasemi Nejad, P.Pahlavani, B.Bigdeli. Automatic building extraction using a decision tree object-based classification on joint use of aerial and lidar data. The International Archives of the Photogrammetry, Remote Sensing and Spatial Information Sciences, Volume XLII-4/W18, 2019. PP.429-434.

3. Гнатушенко В.В. Информационная технология распознавания зданий на многоканальных фотограмметрических изображениях высокого пространственного разрешения на основе морфологических индексов. / В.В.Гнатушенко, А.А.Кавац, Э.Б.Гальченко, Ю.В.Кавац // Вісник ХНТУ. 2016. - №3(58). - C.195-198.

4. Hsiuhan Lexie Yang, Jiangye Yuan, Dalton Lunga, Melanie Laverdiere, Amy Rose, Budhendra Bhaduri. Building Extraction at Scale using Convolutional Neural Network: Mapping of the United States. JOURNAL OF LATEX CLASS FILES, VOL. 14, NO. 8, AUGUST 2015

5. Yongyang $\mathrm{Xu}$, Liang $\mathrm{Wu}$, Zhong Xie, and Zhanlong Chen. Building Extraction in Very High Resolution Remote Sensing Imagery Using Deep Learning and Guided Filters Remote Sens. 2018, 10, 144; doi:10.3390/rs10010144

6. Jianfeng Huanga Xinchang Zhangbc Qinchuan Xinad Ying Sunad Pengcheng Zhange. Automatic building extraction from high-resolution aerial images and LiDAR data using gated residual refinement network/ ISPRS Journal of Photogrammetry and Remote Sensing/ Volume 151, May 2019, Pages 91-105.

7. Соколова Н.О. Распознавание контуров зданий на спутниковых изображениях высокого пространственного разрешения./ Н.О.Соколова // Вестн. Херсон. нац. техн. ун-та. - Херсон, 2015. - №3(54) - С.610-615.

8. Соколова Н.О. Верификация сегментов зданий путем анализа геометрии. / Н.О.Соколова //Вестн. Херсон. нац. техн. ун-та. - Херсон, 2016. №3(58) - C.149-153.

9. Gnatushenko V. The use of geometrical methods in multispectral image processing. Journal of Automation and Information Sciences, Volume 35, 2003 DOI: 10.1615/JAutomatInfScien.v35.i12.10

10. Соколова Н.О. Використання наявності тіні при розпізнаванні будівель на супутникових зображеннях високого розрізнення./ Н.О.Соколова, Є.О.Обиденний. // Вестн. Херсон. нац. техн. ун-та. - Херсон, 2017. №3(62) T.1. - C.345-348.

\section{REFERENCES}

1. Shedlovska Y.I. Shadow detection and removal using a shadow formation model / Y.I. Shedlovska, V.V. Hnatushenko // Proceedings of the 2016 IEEE 1st International Conference on Data Stream Mining and Processing, 2016, August, 23 - 27, Lviv, Ukraine, pp.187-190. 


\section{«Системні технології» 3 (128) 2020 «System technologies»}

2. R.Ghasemi Nejad, P.Pahlavani, B.Bigdeli. Automatic building extraction using a decision tree object-based classification on joint use of aerial and lidar data. The International Archives of the Photogrammetry, Remote Sensing and Spatial Information Sciences, Volume XLII-4/W18, 2019. PP.429-434.

3. Hnatushenko V.V. Informatsionnaya tehnologiya raspoznavaniya zdaniy na mnogokanalnyih fotogrammetricheskih izobrazheniyah vyisokogo prostranstvennogo razresheniya na osnove morfologicheskih indeksov. / V.V.Hnatushenko, A.A.Kavats, E.B.Galchenko, Yu.V.Kavats // VIsnik HNTU. 2016. - \#3(58). - P.195-198.

4. Hsiuhan Lexie Yang, Jiangye Yuan, Dalton Lunga, Melanie Laverdiere, Amy Rose, Budhendra Bhaduri. Building Extraction at Scale using Convolutional Neural Network: Mapping of the United States. JOURNAL OF LATEX CLASS FILES, VOL. 14, NO. 8, AUGUST 2015

5. Yongyang $\mathrm{Xu}$, Liang $\mathrm{Wu}$, Zhong Xie, and Zhanlong Chen. Building Extraction in Very High Resolution Remote Sensing Imagery Using Deep Learning and Guided Filters Remote Sens. 2018, 10, 144; doi:10.3390/rs10010144

6. Jianfeng Huanga Xinchang Zhangbc Qinchuan Xinad Ying Sunad Pengcheng Zhange. Automatic building extraction from high-resolution aerial images and LiDAR data using gated residual refinement network/ ISPRS Journal of Photogrammetry and Remote Sensing/ Volume 151, May 2019, Pages 91-105.

7. Sokolova N.O. Raspoznavanie konturov zdaniy na sputnikovyih izobrazheniyah vyisokogo prostranstvennogo razresheniya. / N.O.Sokolova // Vestn. Herson. nats. tehn. un-ta. - Herson, 2015. - \#3(54) - P.610-615.

8. Sokolova N.O. Verifikatsiya segmentov zdaniy putem analiza geometrii. / N.O.Sokolova //Vestn. Herson. nats. tehn. un-ta. - Herson, 2016. - \#3(58) P.149-153.

9. Gnatushenko V. The use of geometrical methods in multispectral image processing. Journal of Automation and Information Sciences, Volume 35, 2003 DOI: 10.1615/JAutomatInfScien.v35.i12.10

10. Sokolova N.O. Vikoristannya nayavnosti tini pri rozpiznavanni budivel na suputnikovih zobrazhennyah visokogo rozrIznennya. / N.O.Sokolova, E.O.Obidenniy. // Vestn. Herson. nats. tehn. un-ta. - Herson, 2017. - \#3(62) T.1. - P.345-348.

Received 03.02.2020. Accepted 10.02.2020.

Информационная технология автоматизированного распознавания зданий

Данная работа посвящена описанию разработанной информационной технологии для задач распознавания зданий на снимках дистанционного зондирования Земли высоко- 


\section{«Системні технологіï» 3 (128) 2020 «System technologies»}

го разрешения и верификации результатов распознавания. Проанализированы современные подходы к распознаванию зданий. Предложенная технология основана на анализе гистограмм и сегментации в пространстве признаков. Для верификации результатов распознавания разработаны методики на основе геометрического анализа, теневого анализа и использования метаданных. Результатом работы является векторный файл, содержащий распознанные многоугольные объекты.

\section{The information technology for automated recognition building}

The share of space images in the total quantity of Earth remote sensing data is increasing every year. The quality of the data received from the satellites is improving, the accuracy is increasing, the price is being reduced, and the productivity of the new satellites is significantly improving. Automatic building recognition helps save time and system resources for updating geoinformation databases and maintaining up-to-date municipal geodetic data. The analysis of modern methods of building recognition revealed the imperfection of the use of some methods and algorithms, the low number of information technologies for automatic recognition of buildings and the needs to develop a comprehensive approach to address this issue. This paper is devoted to the description of the developed information technology for the tasks of recognizing buildings on high resolution remote sensing images of the Earth and verifying the recognition results. Modern approaches to building recognition are analyzed. Automatic recognition of high resolution satellite images is not effective due to the high heterogeneity of spectral, textural and spatial characteristics. In addition to "preferred" objects (homes and roads), high-resolution images include objects that interfere with spatial recognition (such as trees, cars, and most importantly shadows). The proposed technology is based on five steps: splitting the image into plots with the elimination of vacant plots and determining the type of plot histogram analysis; feature segmentation in image space; validation based on size analysis, geometric and shadow analysis; finding and generalizing the outline of the building. Methods based on geometric analysis, shadow analysis and metadata usage have been developed to verify the recognition results. The result is a vector file that contains recognized polygonal objects. An analysis of commercial buildings has found that a complete run, which includes all stages, improves overall recognition accuracy and reduces manual post processing. Geometry analysis is a crucial step in the overall process with a significant impact on the end result. Size analysis and shadow analysis also play an important role and should be integrated into the process to reduce post-processing efforts.

Соколова Наталя Олегівна - старший викладач кафедри комп’ютерних наук та інформаційних технологій Дніпровського національного університету імені Олеся Гончара (м. Дніпро).

Соколова Наталья Олегівна - старший преподаватель кафедрі компьютерных наук и информационных технологий Днепровского национального университета имени Олеся Гончара (г. Днипро).

Sokolova Natalia - senior lecturer of department of computer science and information technologies, Oles Honchar Dnipro National University, Dnipro, Ukraine. 